\title{
Phylogenetic position of Dendropsophus gaucheri (Lescure and Marty 2000) highlights the need for an in-depth investigation of the phylogenetic relationships of Dendropsophus (Anura: Hylidae)
}

\author{
ANTOINE FOUQUET ${ }^{1,5}$, BRICE P. NOONAN ${ }^{2}$, MICHEL BLANC $^{3} \&$ VICTOR GOYANNES DILL ORRICO $^{4}$ \\ ${ }^{1}$ Universidade de São Paulo, Instituto de Biociências, Departamento de Zoologia \\ Rua do Matão, travessa 14, $n^{o}$ 101, Butantã, CEP: 05422-970 - São Paulo, SP - Brazil - Cx. P. 11441 \\ ${ }^{2}$ University of Mississippi, Department of Biology, Box 1848, MS 38677, USA \\ ${ }^{3}$ Pointe Maripa, RN2/PK35, 97311 Roura, French Guiana \\ ${ }^{4}$ Universidade Estadual Paulista “Júlio de Mesquita Filho”, Instituto de Biociências, Departamento de Zoologia. Av. 24-A, num 1515, \\ Bela Vista, CEP: 13506-900 - Rio Claro, SP - Brazil - CX. P. 199 \\ ${ }^{5}$ Corresponding author. E-mail: fouquet.antoine@gmail.com
}

\begin{abstract}
Dendropsophus gaucheri is a recently described species which inhabits open areas of the eastern part of the Guiana Shield and is currently assigned to the D. parviceps species group based on the presence of a subocular cream spot. Herein we investigate its phylogenetic position including material from the type locality and newly documented populations from Suriname and Brazil based on mtDNA sequences. The species, as well as $D$. riveroi which is assigned to the $D$. minimus species group, were recovered nested within the D. microcephalus species group which implies the paraphyly of the three Dendropsophus species groups. Such result, along with other evidences, highlights the need for a thorough revision of the genus. The genetic distances among D. gaucheri samples studied are low confirming their conspecificity and suggesting recent connections among populations from open areas currently isolated by rainforest in the lowlands of the Guiana Shield.
\end{abstract}

Key words: Amazonia, Dendropsophus parviceps group; Dendropsophus microcephalus group; Distribution; Guiana Shield

\section{Introduction}

Dendropsophus gaucheri (Lescure \& Marty 2000) is a small hylid known only from the type series (three males) from Sinnamary (5.374133, -52.951412), French Guiana (Lescure \& Marty 2000) and by the recent report of nine specimens collected in ESEC Grão-Pará South (-0.165556, -55.186389), northern Pará, Brazil (Ávila-Pires et al. 2010).

The phylogenetic position of $D$. gaucheri remains enigmatic. In the original publication the authors stated that D. gaucheri, D. luteoocellatus (Roux 1927) and another small yet undescribed species of "Hyla" ("Hyla sp. 1" Lescure \& Marty 2000); of French Guiana were part of the D. luteoocellatus group whose diagnostic characteristic was the presence of a subocular cream spot. However, Salducci et al. (2005) recovered "Hyla sp. 1" as allied to D. minusculus and $D$. nanus, two members of the D. microcephalus species group. As noted by Faivovich et al. (2005) the presence of a subocular cream spot is one of the diagnostic characters of the D. parviceps group as defined by Duellman (1970) and Duellman and Crump (1974). Therefore, Faivovich et al. (2005) retained D. gaucheri and D. luteoocellatus in the $D$. parviceps group. Nevertheless, the monophyly of the $D$. parviceps group is dubious according to Faivovich et al. (2005).

Wiens et al. (2006; 2010), Moen and Wiens (2009) and Pyron and Wiens (2011), using molecular data, found the $D$. parviceps species group to be in fact paraphyletic given species assigned to it grouped with various other species groups. To find some species previously assigned to $D$. parviceps species group in fact related to members 